\author{
FEDERAL RESERVE BANK OF SAN FRANCISCO \\ WORKING PAPER SERIES
}

\title{
North-South Technological Diffusion and Dynamic Gains from Trade
}

\author{
Michele Connolly \\ Duke University \\ and \\ Diego Valderrama \\ Federal Reserve Bank of San Francisco
}

Working Paper 2004-24

http://www.frbsf.org/publications/economics/papers/2004/wp04-24bk.pdf

The views in this paper are solely the responsibility of the authors and should not be interpreted as reflecting the views of the Federal Reserve Bank of San Francisco or the Board of Governors of the Federal Reserve System. 


\title{
North-South Technological Diffusion:
}

\section{A New Case for Dynamic Gains from Trade*}

\author{
Michelle Connolly ${ }^{\dagger}$ \\ Diego Valderrama ${ }^{\ddagger}$ \\ Duke University \\ Federal Reserve Bank of San Francisco
}

July 11, 2005

\begin{abstract}
This paper studies the transitional dynamics in a quality ladder model of endogenous growth in which North-South trade leads to technological diffusion through reverse engineering of intermediate goods. The concept of learning-to-learn is incorporated into both imitative and innovative processes, which in turn drive domestic technological progress. International trade with imitation leads to feedback effects between Southern imitators and Northern innovators who compete for the world market. Consequently, both regions face transition paths dependent on their relative technologies. We solve the model numerically to illustrate the transition paths and welfare effects of Southern trade liberalization. While particular welfare results depend on parameter choices, we demonstrate that focusing solely on steady-state results can lead to incorrect welfare interpretations.
\end{abstract}

JEL Codes: F1, F43, O31, O40

Key Words: Technological Diffusion, Learning to Learn, Imitation, Innovation, Dynamic Welfare Effects, Feedback Effects

${ }^{*}$ The views expressed herein are those of the authors and do not necessarily reflect those of the Federal Reserve Bank of San Francisco or the Federal Reserve System. We would like to thank Robert Evenson, Enrique Mendoza, Xavier Sala-i-Martin, and T.N. Srinivasan for their guidance. We also appreciate helpful comments from Amy Glass, James Harrigan, Louise Keely, Kent Kimbrough, Philip Levy, Robert Mundell, Pietro Peretto, David Prentice, and Kei-Mu Yi. We thank Gregory Snyders for valuable research assistance.

${ }^{\dagger}$ Department of Economics, 305 Social Sciences, Box 90097, Durham, NC 27708-0087, USA. Telephone: +1 (919) 660-1819. Facsimile: +1 (919) 684-9874. Email: connolly@econ.duke.edu

${ }^{\ddagger}$ Corresponding author: Economic Research, 101 Market Street, MS 1130, San Francisco, CA 94105, USA. Telephone: +1 (415) 974-3225. Facsimile: +1 (415) 974-2168. Email: Diego.Valderrama@sf.frb.org. 


\section{Introduction}

This paper considers the dynamic implications of North-South trade for both developed and developing nations. In particular, the paper derives the transitional dynamics for both countries resulting from technological diffusion through reverse engineering of traded intermediate goods. Since trade forces competition across countries for markets, the dynamic implications of technological diffusion are critical to understanding not only the evolution of technology in less-developed countries (LDCs) but also the rate of innovation in developed countries (DCs). Most of the current endogenous growth literature emphasizes technology as the engine of growth. Hence, the location of technological innovation, its diffusion, and whether or not this diffusion feeds back and affects the original source of the technology, is crucial to understanding time paths for both DCs and LDCs.

This paper aims to make three contributions to the existing literature on North-South technological diffusion. First, it derives the transitional dynamics of a quality ladder model under free trade. Of particular interest are the transitional dynamics experienced by the South when its firms successfully imitate Northern technology, with the possibility of using imitation to leapfrog Northern firms. One might think of the Japanese automakers, Acura, Lexus, and Infinity, that initially reverse engineered European luxury cars to better design their own luxury automobiles, eventually increasing their share of the luxury automobile market from $4.4 \%$ in 1986 to $26.6 \%$ in $1991 .^{1}$ Second, the paper introduces the notion that both imitation and innovation depend positively on past learning-to-learn in research, whether imitative or innovative. Thus, there is a positive externality both from past imitation and past innovation, although the spillover from innovation is assumed to be greater. Learning-to-learn differs from the more common notion of learning-by-doing in that the skills gained are applicable to different types of research, as opposed to being limited to the exact task in which the learning occurs. Third, the paper explicitly considers imports of Northern capital goods and the quality of Southern communication and transportation infrastructure in modeling the cost of imitation for the South.

There are two strands in the growth literature that consider different aspects of trade and technology. The first strand focuses on the effect of North-South trade when it leads to Northern

\footnotetext{
Bolton 1993 , p. 36).
} 
specialization in industries exhibiting positive spillovers and Southern specialization in industries lacking such positive externalities (Young (1991); Stokey $\left.(1988)^{2}\right)$. Within that type of model, the LDC experiences negative dynamic effects which could potentially outweigh the static gains from trading with a DC. For example, in Young's (1991) model, growth is driven by learning-by-doing in production. This learning-by-doing is bounded within the production of any given good, but exhibits positive spillovers across goods. Once learning-by-doing for a given good is exhausted in one country, then a second country that begins production of the same good will not benefit from any learning-by-doing. Combined with the assumption of no international technological diffusion, this implies that if trade leads an LDC to specialize in the production of goods previously produced in the DC, it will experience technological progress at a rate less than or equal to its autarky rate. Hence, the LDC will face dynamic losses from trade that could possibly outweigh the static gains from trade with a DC.

The second strand of literature considers the effect of North-South trade on technological progress and diffusion (Krugman, 1979, Dollar, 1986, Grossman and Helpman, 1991ab; RiveraBatiz and Romer, 1991, Barro and Sala-i Martin, 1997; Glass, 1997). ${ }^{3}$ In this category of papers, some consider feedback effects between the North and the South in steady state, but do not analyze transitional dynamics for either region (in particular Grossman and Helpman (1991ab)). Barro and Sala-i Martin (1997) derive transitional dynamics for the South but cannot consider the possibility of a feedback effect for the North since they assume no trade in intermediate goods. Hence, no transition path exists for the North.

This paper combines aspects of both strands of the literature. Relative to the first strand, this paper considers what happens if the South specializes in imitation, an activity assumed to have smaller positive externalities than innovation. Relative to the second strand, this paper also considers the effects of North-South trade on technological progress in both regions. Since trade causes a feedback effect between Northern and Southern research, the feedback effect in turn affects not only the steady state, but also the transition to steady state in both the North and the South.

\footnotetext{
${ }^{2}$ Stokey's model considers specialization in a traditional sector with no learning-by-doing versus specialization in industries with learning-by-doing, but does not consider North-South trade.

$\sqrt[3]{\text { Rivera-Batiz and Romer }}(1991)$ consider the effect of increased economic integration through trade between two similar developed countries.
} 
Hence, the issue of North-South trade is considered not only in terms of whether trade leads to Southern specialization in imitation, but also in terms of how such trade affects the diffusion of technology to the South and, in turn, worldwide growth.

Rutherford and Tarr (2002) incorporate expanding intermediate goods varieties as an engine of growth into a computable general equilibrium model. They estimate gains from trade to range from a minimum of $3 \%$ up to a $25 \%$ gain in Hicksian equivalent variation. Our paper incorporates Rutherford and Tarr's notion that access to intermediate goods is important, but it further develops the theoretical model for demonstrating the importance of feedback effects caused by technological diffusion.

We use illustrative numerical examples to demonstrate the importance of considering feedback effects between the North and the South both in transition and in steady state. In particular, we show that under certain parameter choices, Southern Trade liberalization can be welfare reducing for the North, even though it is welfare enhancing in steady-state. Similarly, we demonstrate that Intellectual Property Rights (IPRs) can be potentially welfare enhancing for both countries.

The paper is organized as follows. Section 2 provides empirical motivation for the modeling of imitation. Section 3 develops the model. Section 4 presents results and Section 5 concludes.

\section{Imitation and Learning-to-Learn}

Among the different possible channels of technological diffusion, we are interested in analyzing the role of trade in the diffusion of technology. In particular, we are interested in the reverse engineering of technology embodied in traded goods. Several empirical studies consider the possible link between general imports and technological diffusion (Eaton and Kortum, 1996a b; Coe and Helpman, 1997; Coe et al., 1997; Keller, 1998; Coe and Hoffmaister, 1999). ${ }^{4}$ Trade based convergence clubs also provide evidence that trade is likely an important channel for technological diffusion (Ben-David, 1993, 1996; Ben-David and Rahman, 1996). Moreover, in a survey of 26 U.S. firms whose technology had diffused to non-U.S. competitors, Mansfield and Romeo (1980) found that U.S. firms felt that reverse engineering was the most frequent channel through which technology

\footnotetext{
${ }^{4}$ Coe et al. (1997) consider machine and equipment imports rather than general imports.
} 
"leaked out."

Beyond the static benefits of imitation, reverse engineering leads to learning. Successful imitation by a firm increases that firm's insight into how goods are engineered and improved upon. Imitation not only makes a firm better at future imitation but also improves its chances of successfully inventing the next quality level on its own. For example, Advanced Micro Devices, Inc. and Samsung both initially specialized in reverse engineering and cloning leading edge technology, but have since switched to innovative research.

This learning differs from learning-by-doing in that the skills gained are general and thus applicable to different types of research within an industry. We therefore refer to this as learning-to-learn. This is much like graduate studies, where the first years in graduate school are spent reverse engineering the pre-existing stock of academic knowledge. During that time, students attain the skills and detailed understanding of the subject matter necessary to hopefully "innovate" on their own.

Using panel data for DCs and LDCs, Connolly (2003) finds a significant positive relationship between high technology imports from DCs as a share of GDP and domestic innovation and imitation. ${ }^{5}$ Additionally, there is evidence that importing advanced Northern capital goods lowers the Southern cost of imitation because of general exposure to imports, ${ }^{6}$ and servicing and distribution by local importing firms. ${ }^{7}$ Finally, trade increases the incentives to imitate by providing access to larger international markets. ${ }^{8}$

The process of learning-to-learn suggests that a country that is handed technology will not be able to move beyond that technology as easily as if the country had created or imitated that tech-

\footnotetext{
${ }^{5}$ Connolly further finds that the importance of high technology imports to domestic research is greater in LDCs countries than in DCs countries. This may reflect the fact that, since LDCs are often not highly integrated with DCs, the role of trade in physical goods is all the more important for the diffusion of technology to the LDC. Thus trade appears to play an important role in technological diffusion and, in turn, conditional convergence, particularly for LDCs nations.

${ }^{6}$ For example, if each individual exposed to a good has a certain probability of imitating it, then the number of people exposed to the good should positively affect the overall probability that the good is imitated.

[Lesley (1924) provides anecdotal evidence of three independent U.S. imitations of previously imported European Portland cement during the late 1800s: by an individual who used Portland cement in construction, by a company that made concrete products, and by a large importing firm that distributed Portland cement within the U.S. The importance of exposure to a good is also demonstrated in Thomson's (1987) study of 3,500 U.S. sewing machine patents, in which he finds that patenting activity followed sewing machine sales both geographically and temporally.

${ }^{8}$ Sokoloff (1988) finds that U.S. counties from 1790 to 1846 with access to navigable waterways had higher patenting rates than counties without such access. Moreover, he finds an increase in county patenting rates after the introduction of new waterways in or adjacent to these counties. Thus, both exposure to goods and access to larger markets appear to play important roles in research activity.
} 
nology on its own. There is therefore an issue of hysteresis to be considered, which has important implications for LDCs and their technological development.

\section{The Model}

We model technological diffusion through reverse engineering of technology embodied in intermediate goods. We assume no domestic or international enforcement of intellectual property rights. The South experiences learning-to-learn effects even if trade with the North leads to Southern specialization in imitative research. As long as the South clones goods that it did not previously produce, it benefits from learning-to-learn in research. ${ }^{9,10}$

The effects of international trade with imitation are considered, assuming that the two countries are starting from steady-state positions with partial Southern trade barriers and the North is the lead innovating country. Trade is balanced at all times so there are no international capital flows. The domestic interest rate is determined by domestic technology. With trade, firms can use imports of intermediate goods in final goods production. Southern firms will import any intermediate goods that have not yet been copied, and export the Southern final good, as well as any lead intermediate goods that they have reverse engineered. ${ }^{11}$ Since the South can immediately import higher quality Northern intermediate goods for use in final goods production, it is not limited by its own ability to produce intermediate goods. With sufficiently low trade barriers, both Northern and Southern output growth will be determined by Northern technological progress.

Furthermore, since importing firms are responsible for distributing and servicing these intermediate goods, they learn a great deal about the goods they are selling. They learn which products are in greatest demand, what are the most recent developments within the industry, how to adapt the goods to local conditions if necessary, and how to fix or replace the goods they sell. Hence,

\footnotetext{
${ }^{9}$ This contrasts with Young's (1991) model, which assumes that if learning-by-doing for a given good is exhausted in one country, then a second country which begins production of the same good will not benefit from any learningby-doing.

10 van Elkan (1996) considers the issue of human capital accumulation and technological diffusion. For tractability, we consider research experience without specifically modeling it as human capital.

${ }^{11}$ With lower equilibrium Southern marginal costs of production, Southern firms can underprice lead Northern firms. Hence, both countries will switch to using copied intermediate goods in their final goods production whenever available.
} 
importing intermediate goods lowers the cost of imitation. Thus, for a given infrastructure level and past learning-to-learn, countries with greater openness to imports face lower costs of imitation.

As trade barriers decrease, Northern firms will be able to sell to a larger market but will now be concerned with the joint probability of losing their market either to the next innovation or to a lower-priced imitation. Relative to being closed to intermediate goods imports, where Southern firms only needed to imitate Northern goods one quality rung above the current Southern quality level, trade forces Southern firms to imitate lead Northern goods, possibly several quality rungs above their own experience level. Still, since trade in physical goods allows for reverse engineering, it is possible for Southern firms to imitate Northern goods several quality levels ahead of the technology currently produced in the South. The cost and speed of imitation in each sector will depend on exactly how large a technology gap needs to be bridged by Southern imitators.

\subsection{Quality Ladder Model}

We begin from a conventional quality ladder model (Grossman and Helpman, 1991a b; Aghion and Howitt, 1992, Barro and Sala-i Martin, 1995, 1997). There are a fixed number, J, of intermediate sectors. With limit pricing, only the highest-quality good will be sold in each sector. The quality of each good increases with successful innovations. Each quality improvement can be thought of as stepping one rung further up a ladder. The size of each step reflects the size of quality improvements. As often assumed, we set the size of this step to be a constant, $q$, greater than 1 . The rung at which the good is located on a quality ladder is denoted by $k$. Normalizing so all goods begin at quality level 1, the quality level of an intermediate good in sector $j$ will rise from 1 to $q$ with the first innovation, to $q^{2}$ with the second innovation, and to $q^{k_{j}}$ with the $k_{j}$ th innovation.

Since technology is embodied in intermediate goods, output growth in each country is driven by technological advances in the quality of domestically available inputs, regardless of country of origin. We extend the basic setup of Barro and Sala-i Martin (1995, Ch. 7) to an open economy situation. The resulting aggregate final goods production function, undertaken by many perfectly 
competitive firms, in the North (country N) and the South (country S) is:

$$
Y_{i}=A_{i} L_{i} \sum_{j=1}^{J}\left(q^{k_{N_{j}}} \hat{x}_{i k_{j}}\right)^{1-\alpha}, i \in\{N, S\}
$$

$A$ is a productivity parameter dependent upon the country's institutions, such as tax laws, property rights, and government services, and $L$ is the labor input used by the representative firm for final

goods production. $q^{k_{N_{j}}} \hat{x}_{i k_{j}}$ is the quality-adjusted level of intermediate good $j$ used in final goods production. This intermediate good can be domestic or foreign-produced. From equation (3.1) we see that, as the quality level of intermediate goods rises, so does the final goods output. Each country produces a different final good. Let the final good in the North, $Y_{N}$, be the numeraire, so $P_{N}=1$. The Southern final good, $Y_{S}$, has price $P_{S}$.

\subsection{Consumer's Problem}

The Northern consumer makes consumption and savings decisions to maximize the present value lifetime utility

$$
\begin{gathered}
\max _{\left\{C_{N}, C_{S}^{*}, v\right\}_{t \rightarrow \infty}} \int_{0}^{\infty} u\left(\bar{C}_{N}\right) e^{-\rho t} d t \\
u\left(\bar{C}_{N}\right)=\left(\frac{\bar{C}_{N}^{1-\theta}-1}{1-\theta}\right) \\
\bar{C}_{N}=C_{N}^{\kappa} C_{S}^{* 1-\kappa} \\
\dot{v}=w+r_{N} v-E_{N} \\
E_{N}=P_{N} C_{N}+P_{S}^{*} C_{S}^{*} .
\end{gathered}
$$

Equation (3.4) is a Cobb Douglas aggregator that defines the Northern composite good, $\bar{C}_{N}$, in terms of Northern and Southern final goods consumed in the North, $C_{N}$ and $C_{S}^{*}$, respectively, with domestic expenditure-share parameter $\kappa$. The intertemporal elasticity of substitution is $\frac{1}{\theta}$. The return to assets, $v$, in the North is $r_{N}$, and the wage rate is $w$. One unit of labor is supplied inelastically every period. Equation (3.5) states the evolution of the value of assets, $\dot{v}$, as the 
difference of labor and interest income minus Northern consumption expenditures, $E_{N}$. Equation (3.6) gives total expenditures by the North, $E_{N}$.

The consumption-based price index, $\bar{P}_{N}$, is defined as the minimum expenditure, $E_{N}$, such that the composite good index, $\bar{C}_{N}=1$, for a given set of prices (Obstfeld and Rogoff, 1996, Ch. 4):

$$
\bar{P}_{N}=\left(\frac{P_{N}}{\kappa}\right)^{\kappa}\left(\frac{P_{S}^{*}}{1-\kappa}\right)^{1-\kappa}
$$

Given standard calculations, we obtain two expressions for consumer demands:

$$
\begin{gathered}
C_{N}=\kappa \frac{\bar{P}_{N}}{P_{N}} \bar{C}_{N} \\
C_{S}^{*}=(1-\kappa) \frac{\bar{P}_{N}}{P_{S}^{*}} \bar{C}_{N} .
\end{gathered}
$$

Substituting these expressions into the household's utility maximization problem yields the usual expression for consumption growth:

$$
\frac{\dot{\bar{C}}_{N}}{\bar{C}_{N}}=\frac{1}{\theta}\left(r_{N}-\frac{\dot{\bar{P}}_{N}}{\bar{P}_{N}}-\rho\right)
$$

The problem of the Southern household is entirely symmetric:

$$
\begin{gathered}
\max _{\left\{C_{N}^{*}, C_{S}, v\right\}_{t \rightarrow \infty}} \int_{0}^{\infty} u\left(\bar{C}_{S}\right) e^{-\rho t} d t \\
u\left(\bar{C}_{S}\right)=\left(\frac{\bar{C}_{S}^{1-\theta}-1}{1-\theta}\right) \\
\bar{C}_{S}=C_{N}^{* 1-\beta} C_{S}^{\beta} \\
\dot{v}=w+r_{S} v-E_{S} \\
E_{S}=P_{S} C_{S}+P_{N}^{*} C_{N}^{*} .
\end{gathered}
$$

We assume that both countries spend the same proportion on the goods produced in the North, 
(i.e., $\beta=1-\kappa$ ). The resulting expression for the Southern households' demand functions are

$$
\begin{gathered}
\bar{P}_{S}=\left(\frac{P_{N}^{*}}{\kappa}\right)^{(\kappa)}\left(\frac{P_{S}}{1-\kappa}\right)^{(1-\kappa)} \\
C_{N}^{*}=\kappa \frac{\bar{P}_{S}}{P_{N}^{*}} \bar{C}_{S} \\
C_{S}=(1-\kappa) \frac{\bar{P}_{S}}{P_{S}} \bar{C}_{S}
\end{gathered}
$$

Finally, by assumption, the relative price of the Southern final good adjusts to balance trade at all times:

$$
P_{S}=\frac{P_{N}\left(1+\tau_{Y S}+t\right) C_{N}^{*}+P_{N S}^{*} n_{N S} X_{N S}^{*}+P_{N N}^{*} n_{N N} X_{N N}^{*}-P_{S N}^{*} n_{S N} X_{S}^{*}}{\left(1+\tau_{Y N}+t\right) C_{S}^{*}} .
$$

\subsection{Industrial Structure}

Which country actually produces the intermediate goods used in final goods production depends on each country's technological level, as well as trade barriers. By assumption, the North is the more technologically advanced country. Therefore it must innovate to push forward its (and the world's) technology frontier. The South can increase its domestic technology by imitating Northern technology, at least until the gap in their technology levels is eliminated.

Once knowledge of how to produce an intermediate good exists domestically, it can be produced using the final goods production function. Therefore, the marginal cost of producing an intermediate good equals the marginal cost, $M C_{i}$, of producing the final good. With perfect competition in the final goods industry, this also equals the price of the final good (i.e., $M C_{i}=P_{Y i}$ ). So the marginal cost of producing an intermediate good is independent of its quality level and is identical across all domestic sectors. Since the Northern final good is numeraire, $M C_{N}=1$. Further, we assume parameters yielding equilibrium marginal costs that are greater in the North than in the South $\left(M C_{N}>M C_{S}\right)$. This enables a successfully imitating Southern firm to capture the world market.

We assume that knowledge of how to make a good is public knowledge within a country. ${ }^{12}$ The

\footnotetext{
${ }^{12}$ One could think of countries as having domestically enforced patents that protect the lead firm's domestic
} 
lead innovating firm in each sector uses limit pricing to wipe out sales of lower-quality intermediate goods in its sector. ${ }^{13}$ Innovations are drastic $\left(q>\frac{\left(1+\tau_{x_{S}}+t\right)}{M C_{S}}\right)$. That is, the size of quality improvements is large enough that a Northern firm can hold the world market with a single quality level improvement over a Southern copy. A Southern firm can capture the world market by imitating (and underpricing) the lead Northern good. Hence, there is a Vernon-type product cycle where production shifts from the North to the South with successful Southern imitation and back with subsequent Northern innovation.

Firms decide how many resources to devote to research based on the expected present value of profits for successful research, which depends on the probabilities of innovation and imitation. Within an intermediate goods sector $j$, presently at quality level $k_{N j}, p_{I k_{N j}}$ is the probability per unit of time that the $\left(k_{N j}+1\right)$ th innovation occurs. $p_{I k_{N j}}$ follows a Poisson process, which depends positively on resources devoted to research, $z_{I k_{N j}}$, and past industry-specific domestic learning-tolearn, $\vartheta_{k_{N j}}$, and negatively on the complexity, $\varphi_{I k_{N j}}$, of the good upon which firms are attempting to improve: ${ }^{14}$

$$
\begin{aligned}
p_{I k_{N j}} & =z_{I k_{N j}} \vartheta_{k_{N j}} \varphi_{I k_{N j}}, \quad \text { where } \\
\vartheta_{k_{N j}} & =\beta_{I} q^{k_{N j}}, \quad \text { and } \\
\varphi_{I k_{N j}} & =\frac{1}{\zeta_{I}} q^{\frac{-k_{N j}}{\alpha}} .
\end{aligned}
$$

$\beta_{I}$ reflects a positive spillover from past experience, while $\zeta_{I}$ is a fixed cost of innovative research.

monopoly of that quality good, while at the same time costlessly disseminating acquired knowledge to other domestic firms.

${ }^{13}$ Even without domestic IPR protection, the existence of any fixed cost to imitation will effectively preclude domestic imitation of a domestic good.

${ }^{14}$ The forms assumed for $\vartheta$ and $\varphi$ guarantee constant returns to innovative research with respect to current technology levels $\left(k_{i j}\right)$. This is needed to consider a balanced growth path in steady state. Furthermore, this setup is reasonable if there are an infinite number of potential innovations, implying no diminishing returns to innovative research and development (Romer, 1990). 
The probability, $p_{C k_{N j}}$, of imitating the current lead technology, $k_{N j}$, follows a similar form:

$$
\begin{aligned}
p_{C k_{N j}} & =z_{C k_{N j}} \vartheta_{k_{S j}} \varphi_{I k_{N j}}, \quad \text { where } \\
\vartheta_{k_{N j}} & =\max \left(\beta_{C} q^{k_{S j}}, \beta_{I} q^{k_{N j}}\right), \\
\varphi_{C k_{N j}} & =\frac{e^{\omega}}{\zeta_{C} \hat{q}_{j}^{\sigma}} q^{\frac{-k_{N j}}{\alpha}} \text { for } \quad \sigma>1, \\
\hat{q}_{j} & =\frac{q^{k_{S j}}}{q^{k_{N j}}}, \quad \text { and } \\
\omega & =\left(\frac{M}{Q_{N}}\right)^{\eta} .
\end{aligned}
$$

Learning in the South depends on the highest past experience within that sector whether gained through imitation or through innovation. ${ }^{15}$ We assume that the spillover from past innovative experience, $\beta_{I}$, is greater than those from imitation, $\beta_{C}$. Similarly, the fixed cost of imitation, $\zeta_{C}$, is assumed to be less than the cost of innovation, $\zeta_{I} \cdot{ }^{16}$ Relative to the cost of innovation, two new factors affect the cost of imitation, $\frac{\zeta_{C} \hat{q}_{j}^{\sigma}}{e^{\omega}}$. First, the cost of imitation depends positively on the sector $j$ South/North technology ratio, $\hat{q}_{j}$, and reflects the increasing cost of imitation as Southern technology approaches that of the North. Hence, there are decreasing returns to imitation as the pool of goods that can be targeted for imitation decreases. The parameter $\sigma$ affects how quickly the cost of imitation rises as the technology gap falls. ${ }^{17}$ Second, the cost depends negatively on the interaction, $\omega$, between the two countries. This is measured by Southern openness to imports of intermediate goods, $M$, scaled by the aggregate Northern technology level, $Q_{N}=\sum_{j=1}^{J} q^{\frac{k_{N j}(1-\alpha)}{\alpha}}$. Since the cost of imitation is increasing as the North-South technology gap decreases, the probability of imitation and, consequently, the probability of innovation both change in transition to steady state.

With monopolistic competition in the intermediate good sectors, expected profits depend on the type of competition faced by the firm. There are three different types of firms: Northern firms facing Northern competition, $n_{N N}$, Northern firms facing Southern competition, $n_{N S}$, and Southern

\footnotetext{
${ }^{15}$ If the sector has no imitative experience, then $q^{k_{S j}}=0$, and if it has no innovative experience, then $q^{k_{N j}}=0$.

${ }^{16}$ This is consistent with the empirical findings of Mansfield et al. (1981).

${ }^{17}$ Since the experienced gained from imitation increases one-to-one with $\hat{q}, \sigma$ must be greater than 1 for the probability of imitation to fall as $\hat{q}$ increases. This guarantees a smooth transition.
} 
imitating firms facing Northern competition, $n_{S}$. Since there are $J$ sectors, $J=n_{S}+n_{N S}+n_{N N}{ }^{18}$

Entry and exit into these three categories depends on $p_{I}$ and $p_{C}$ :

$$
\begin{aligned}
\dot{n}_{N N} & =p_{I}\left(1-p_{C}\right) n_{N S}-\left[p_{I} p_{C}+\left(1-p_{I}\right) p_{C}\right] n_{N N} \\
\dot{n}_{N S} & =p_{I}\left(p_{C} n_{N N}+n_{S}\right)-\left[\left(1-p_{I}\right) p_{C}+p_{I}\left(1-p_{C}\right)\right] n_{N S} \\
\dot{n}_{S} & =\left(1-p_{I}\right) p_{C}\left(n_{N N}^{*}+n_{N S}^{*}\right)-p_{I} n_{S} .
\end{aligned}
$$

From these entry-exit conditions, we can find expressions for the steady-state decomposition of intermediate goods sectors into these three categories:

$$
\begin{aligned}
n_{S} & =\frac{\left(1-p_{C}\right) J}{2-p_{C}} \\
n_{N N} & =\frac{n_{S}}{1-p_{C}} \\
n_{N S} & =\frac{n_{N N}}{1-p_{C}} .
\end{aligned}
$$

Northern firms facing Northern competition choose a limit price slightly below $q$ times the lowest price at which the previous innovator could sell, since their product is $q$ times more productive than its predecessor. $M C_{N}=1$ is the lowest price at which the previous innovator could sell in the North, and $\left(1+\tau_{x_{S}}+t\right)$ is the lowest price at which it could sell in the South without earning negative profits since they face Southern tariffs on intermediates of $\tau_{x_{S}}$ and ad-valorem transportation costs, $t$. So for Northern firms facing Northern competition, $n_{N N}$, they will have two limit prices: $P_{N N}=q M C_{N}=q$ for domestic sales, and $P_{N N}^{*}=q\left(1+\tau_{x_{S}}+t\right)$ for exports to the South. ${ }^{19}$ At these limit prices, world sales of all older technologies will be wiped out. Similarly, Northern firms facing Southern competition, $n_{N S}$, will have limit prices $P_{N S}=q M C_{S}\left(1+\tau_{x_{S}}+t\right)$ domestically and $P_{N S}^{*}=q M C_{S}$ abroad. Southern firms, $n_{S}$, always face Northern competition and choose limit prices $P_{S}^{*}=1$ for exports to the North and $P_{S}=1+\tau_{x_{S}}+t$ for domestic sales.

In either country $i$, for a given limit price, $P_{x}$, and final goods price, $P_{i}$, implied demand for

\footnotetext{
${ }^{18}$ We set the mass $J=1$, so that $n$ will represent the percent of the Southern market held by each category.

${ }^{19}$ This holds if $q(1-\alpha) \leq 1$. If instead $q(1-\alpha)>1$, then Northern firms will use monopoly pricing.
} 
intermediate goods in sector $j$ is

$$
x_{i j}=L_{i}\left[A_{i}(1-\alpha) q^{k_{i j}(1-\alpha)} \frac{P_{i}}{P_{x}}\right]^{\frac{1}{\alpha}} .
$$

Substituting into (3.1) for the appropriate limit prices, $M C_{i}$ for $P_{Y_{i}}$, and aggregating across intermediate goods sectors obtains expressions for aggregate output in each country:

$$
\begin{aligned}
& Y_{N}=Q_{N} \Lambda_{N}\left[n_{N N}+n_{N S}\left(1+\tau_{x_{N}}+t\right)^{\frac{\alpha-1}{\alpha}} M C_{S}^{\frac{\alpha-1}{\alpha}}+n_{S} q^{\frac{1-\alpha}{\alpha}}\right] \\
& Y_{S}=Q_{N} \Lambda_{S}\left[n_{N N}\left(\frac{M C_{S}}{1+\tau_{x_{S}}+t}\right)^{\frac{1-\alpha}{\alpha}}+n_{N S}+n_{S} q^{\frac{1-\alpha}{\alpha}}\left(\frac{M C_{S}}{1+\tau_{x_{S}}+t}\right)^{\frac{1-\alpha}{\alpha}}\right] \\
& \text { where } Q_{N}=\sum_{j=1}^{J} q^{\frac{k_{N j}(1-\alpha)}{\alpha}} \quad \text { and } \quad \Lambda_{S}=L_{S} A_{S}^{1 / \alpha}\left(\frac{1-\alpha}{q}\right)^{\frac{1-\alpha}{\alpha}}
\end{aligned}
$$

$Q_{N}$ represents the Northern aggregate quality index. Note that aggregate production in both countries depends on $Q_{N}$, since limit pricing with free trade insures that only the highest quality technology will be used. Hence, even when an intermediate good is produced in the South, its quality level is the same as the lead Northern quality level. In steady state, sector shares, $n_{N N}$, $n_{N S}$, and $n_{S}$, will be constant. Both countries' steady-state growth rates depend solely on Northern technological progress, at least so long as the North remains the lead innovating country. Still, international trade and the subsequent risk of losing the market for a given intermediate good to Southern imitation causes the Northern rate of innovation to depend on the Southern rate of imitation.

\subsection{Transitional Dynamics}

The model dynamics depend on the rate of innovation and imitation, the relative level of the two technologies, the rate of growth of consumption in each country, and the relative price level. We now obtain expressions for the resources available to research and development by using the world resource constraints There are two world resource constraints reflecting that each final good can 
be consumed, used for research, or costlessly transformed into intermediate goods:

$$
\begin{aligned}
Y_{N} & =C_{N}+X_{N}+Z_{N}+C_{N}^{*}+X_{N}^{*}+\text { TRANS }_{N} \\
Y_{S} & =C_{S}+X_{S}+Z_{S}+C_{S}^{*}+X_{S}^{*}+\mathbf{T R A N S}_{S}, \quad \text { where } \\
\text { TRANS }_{N} & =t\left(\frac{P_{N S}^{*}}{1+\tau_{X S}+t} n_{N S} X_{N S}^{*}+\frac{P_{N N}^{*}}{1+\tau_{X S}+t} n_{N N} X_{N N}^{*}+C_{N}^{*}\right), \\
\text { TRANS }_{S} & =t\left(\frac{P_{N S}^{*}}{1+\tau_{X N}+t} n_{N S} X_{N S}^{*}+P_{S} C_{S}^{*}\right) \\
X_{N} & =n_{N S} X_{N S}+n_{N N} X_{N N}, X_{N}^{*}=n_{N S} X_{N S}^{*}+n_{N N} X_{N N}^{*}, \quad \text { and } \\
X_{S} & =n_{N S} X_{S}, \text { and } X_{S}^{*}=n_{N S} X_{S}^{*} .
\end{aligned}
$$

TRANS $_{N}$ and TRANS $_{S}$ reflect ad-valorem transportation costs (based on free on board prices) and asterisks, $*$, denote exports.

Substituting into the two resource constraints, 3.29 ) and 3.30 , for the $Y_{i}$ from the production functions, (3.27) and (3.28), and for the $X_{i}$ from the implied demand functions, (3.26), yields an expression for total resources, $Z_{i}$, available for research in each country:

$$
\begin{aligned}
Z_{N}=Q_{N} & \left\{\Lambda _ { N } \left[n_{N S}\left(1+\tau_{X N}+t\right)^{\frac{\alpha-1}{\alpha}} M C_{S}^{\frac{\alpha-1}{\alpha}}+n_{N N}\right.\right. \\
& \left.+n_{S} q^{\frac{1-\alpha}{\alpha}}-\frac{1-\alpha}{q}\left(n_{N S}\left(1+\tau_{X N}+t\right)^{\frac{-1}{\alpha}} M C_{S}^{\frac{-1}{\alpha}}+n_{N N}\right)\right] \\
& -\Lambda_{S} \frac{1-\alpha}{q}\left[n_{N S}\left(1+\frac{t q M C_{S}}{1+\tau_{X S}+t}\right)+n_{N N}\left(\frac{M C_{S}}{1+\tau_{X S}+t}\right)^{\frac{1}{\alpha}}(1+t q)\right] \\
& \left.-\chi_{N}-(1+t) \chi_{N}^{*}\right\} \\
Z_{S}=Q_{N} & \left\langle\Lambda _ { S } \left\{ n_{N S}+n_{N N}\left(\frac{M C_{S}}{1+\tau_{X S}+t}\right)^{\frac{1-\alpha}{\alpha}}\right.\right. \\
& \left.+n_{S} q^{\frac{1-\alpha}{\alpha}}\left[\left(\frac{M C_{S}}{1+\tau_{X S}+t}\right)^{\frac{1-\alpha}{\alpha}}-(1-\alpha)\left(\frac{M C_{S}}{1+\tau_{X S}+t}\right)^{\frac{1}{\alpha}}\right]\right\} \\
& \left.-\Lambda_{N} n_{S}(1-\alpha) q^{\frac{1-\alpha}{\alpha}}\left(1+\frac{t}{1+\tau_{X N}+t}\right)-\chi_{S}-\left(1+t M C_{S}\right) \chi_{S}^{*}\right\rangle
\end{aligned}
$$

where $\chi_{N}=\frac{C_{N}}{Q_{N}}, \chi_{N}^{*}=\frac{C_{N}^{*}}{Q_{N}}, \chi_{S}=\frac{C_{S}}{Q_{N}}$, and $\chi_{S}^{*}=\frac{C_{S}^{*}}{Q_{N}}$. 
Since the probabilities of innovation and imitation of a particular industry depend on the South/North technology ratio within that industry, these equilibrium probabilities are industryspecific. However, to characterize the transition path for the aggregate economies, it is sufficient to consider the average domestic industry (denoted by the subscript $a$ ). Average resources devoted to research, $Z_{i a}=\frac{Z_{i}}{J}$, can be put into (3.20) and (3.21) to yield expressions for the probabilities of innovation and imitation in the average sector. Moreover, the cost of imitation, and hence the probability of imitation for the average sector, depends on the average South/North technology ratio, which equals the aggregate South/North technology ratio, $\hat{Q}=\frac{Q_{S}}{Q_{N}}$. Hence,

$$
\begin{aligned}
p_{I k_{N a}}= & \frac{\beta_{I}}{\zeta_{I}}\left\{\Lambda _ { N } \left[n_{N S}\left(1+\tau_{X N}+t\right)^{\frac{\alpha-1}{\alpha}} M C_{S}^{\frac{\alpha-1}{\alpha}}+n_{N N}+n_{S} q^{\frac{1-\alpha}{\alpha}}\right.\right. \\
& \left.-\frac{1-\alpha}{q}\left(n_{N S}\left(1+\tau_{X N}+t\right)^{\frac{-1}{\alpha}} M C_{S}^{\frac{-1}{\alpha}}+n_{N N}\right)\right] \\
& -\Lambda_{S} \frac{1-\alpha}{q}\left[n_{N S}\left(1+\frac{t q M C_{S}}{1+\tau_{X S}+t}\right)+n_{N N}\left(\frac{M C_{S}}{1+\tau_{X S}+t}\right)^{\frac{1}{\alpha}}(1+t q)\right] \\
& \left.-\chi_{N}-(1+t) \chi_{N}^{*}\right\} \\
p_{C k_{N a}}= & \frac{\beta_{C} e^{\omega}}{\zeta_{C}} \hat{Q}^{1-\sigma}\left\langle\Lambda _ { S } \left\{ n_{N S}+n_{N N}\left(\frac{M C_{S}}{1+\tau_{X S}+t}\right)^{\frac{1-\alpha}{\alpha}}\right.\right. \\
& \left.+n_{S} q^{\frac{1-\alpha}{\alpha}}\left[\left(\frac{M C_{S}}{1+\tau_{X S}+t}\right)^{\frac{1-\alpha}{\alpha}}-(1-\alpha)\left(\frac{M C_{S}}{1+\tau_{X S}+t}\right)^{\frac{1}{\alpha}}\right]\right\} \\
& \left.-\Lambda_{N} n_{S}(1-\alpha) q^{\frac{1-\alpha}{\alpha}}\left(1+\frac{t}{1+\tau_{X N}+t}\right)-\chi_{S}-\left(1+t M C_{S}\right) \chi_{S}^{*}\right\rangle .
\end{aligned}
$$

Since the probabilities of innovation and imitation in the average industry change with $\hat{Q}$, interest rates and growth rates will also change during the transition to steady state. From these probabilities, we have an expression for the evolution of the South/North technology ratio

$$
\frac{\dot{\hat{Q}}}{\hat{Q}}=\frac{\dot{Q}_{S}}{Q_{S}}-\frac{\dot{Q}_{N}}{Q_{N}}=\left(q^{\frac{1-\alpha}{\alpha}}-1\right)\left(p_{C k_{N a}}-p_{I k_{N a}}\right) .
$$

Interest rates, $r_{N}$ and $r_{S}$, will be determined by two free-entry conditions which state that with free entry firms will continue devoting resources to research until they exactly equal the expected 
present value of profits

$$
\begin{aligned}
p_{I k_{N a}} E\left(v_{I k_{N a}+1}\right) & =Z_{I k_{N a}} \\
p_{C k_{N a}} E\left(v_{C k_{N a}}\right) & =Z_{C k_{N a}}, \quad \text { where } \\
E\left(v_{I k_{N a}+1}\right) & =\pi_{I k_{N a}+1} \int_{t}^{\infty} e^{-\int_{t}^{s}\left[r_{N}(v)+p_{C k_{N a}+1}(v)+p_{I k_{N a}+1}(v)-p_{C k_{N a}+1}(v) p_{I k_{N a}+1}(v)\right] d v} d s \\
E\left(v_{C k_{N a}}\right) & =\pi_{C k_{N a}} \int_{t}^{\infty} e^{-\int_{t}^{s}\left[r_{S}(v)+p_{I k_{N a}}(v)\right] d v} d s .
\end{aligned}
$$

and

The $E(v)$ in equations (3.36) and (3.37) represent the expected present value of profits from successful research. In the case of innovation, it is discounted by the Northern interest rate and by the probability of losing sales to either imitation or to the $\left(k_{N a}+2\right) t h$ innovation. In the case of imitation, it is discounted by the Southern interest rate and the probability of losing sales to the $\left(k_{N a}+1\right)$ th innovation. Differentiating both sides of the free-entry conditions (using Leibniz's rule for the left-hand side of the equations) yields expressions for the interest rates in both countries

$$
\begin{aligned}
r_{N}= & \frac{p_{I k_{N a}} \pi_{I k_{N a}+1}}{Z_{I k_{N a}}}+\frac{\dot{Z}_{I k_{N a}}}{Z_{I k_{N a}}}-\frac{\dot{p}_{I k_{N a}}}{p_{I k_{N a}}}-\frac{\dot{\pi}_{I k_{N a}+1}}{\pi_{I k_{N a}+1}} \\
& -p_{C k_{N a}+1}-p_{I k_{N a}+1}+p_{C k_{N a}+1} p_{I k_{N a}+1} \\
r_{S}= & \frac{p_{C k_{N a}} \pi_{C k_{N a}}}{Z_{C k_{N a}}}+\frac{\dot{Z}_{C k_{N a}}}{Z_{C k_{N a}}}-\frac{\dot{p}_{C k_{N a}}}{p_{C k_{N a}}}-\frac{\dot{\pi}_{C k_{N a}}}{\pi_{C k_{N a}}}-p_{I k_{N a}} .
\end{aligned}
$$

We can derive two consumption growth conditions by taking natural logs and derivatives of (3.8) and (3.18) and substituting in for the growth rates of aggregate consumption (3.10) and for the price indexes (by taking logs and derivatives of (3.7) and (3.16)

$$
\begin{aligned}
& \frac{\dot{C}_{N}}{C_{N}}=(1-\kappa) \frac{\dot{P}_{S}^{*}}{P_{S}^{*}}+\frac{1}{\theta}\left(r_{N}-\rho-(1-\kappa) \frac{\dot{P}_{S}^{*}}{P_{S}^{*}}\right) \\
& \frac{\dot{C}_{S}}{C_{S}}=-\kappa \frac{\dot{P}_{S}}{P_{S}}+\frac{1}{\theta}\left(r_{S}-\rho-(1-\kappa) \frac{\dot{P}_{S}}{P_{S}}\right) .
\end{aligned}
$$




$$
\begin{aligned}
& \text { Since } \chi_{N}=\frac{C_{N}}{Q_{N}} \text { and } \chi_{S}=\frac{C_{S}}{Q_{N}}, \\
& \frac{\dot{\chi}_{N}}{\chi_{N}}=\frac{\dot{C}_{N}}{C_{N}}-\frac{\dot{Q}_{N}}{Q_{N}}=(1-\kappa) \frac{\dot{P}_{S}^{*}}{P_{S}^{*}}+\frac{1}{\theta}\left(r_{N}-\rho-(1-\kappa) \frac{\dot{P}_{S}^{*}}{P_{S}^{*}}\right)-\left(q^{\frac{1-\alpha}{\alpha}}-1\right) p_{I k_{N a}} \\
& \frac{\dot{\chi}_{S}}{\chi_{S}}=\frac{\dot{C}_{S}}{C_{S}}-\frac{\dot{Q}_{N}}{Q_{N}}=-\kappa \frac{\dot{P}_{S}}{P_{S}}+\frac{1}{\theta}\left(r_{S}-\rho-(1-\kappa) \frac{\dot{P}_{S}}{P_{S}}\right)-\left(q^{\frac{1-\alpha}{\alpha}}-1\right) p_{I k_{N a}} .
\end{aligned}
$$

These expressions show that in steady state there will be interest rate equalization between the two countries. So even though there are no international capital flows, the diffusion of technology is sufficient to yield interest rate equalization.

Using these two equations in (3.40), two of our firm category net entry conditions (3.23) and (3.24), and the expression for growth of the South/North technology ratio 3.35 gives us a system of five differential equations in the variables $\hat{Q}, \chi_{N}, \chi_{S}, n_{N S}$, and $n_{S}$. Together with three initial conditions for $\hat{Q}, n_{N S}$, and $n_{S}$, these describe the transition paths for the North and the South.

\section{Results}

We solve the model numerically for reasonable parameter values. The solution method works by linearizing the five differential equations that characterize the model dynamics around the balanced growth path. Benchmark parameter values are based on theoretical and empirical priors. Table 1 describes the choice of parameter values. Further, a wide range of parameter values yield similar stable saddle paths to steady state, differing principally in terms of the steady-state levels of $\hat{Q}$, $n_{N S}, n_{S}, \chi_{N}$, and $\chi_{S}$ to which they approach. ${ }^{20}$

Figure 11 shows the transition path for key variables for the South as it moves from having tariffs of $5 \%$ to $1 \%$ on all imports. It should be noted that, given our system of five differential equations and three state variables, we have three negative eigenvalues determining the evolution of the system. As noted in Eicher and Turnovsky (2001), the presence of multiple eigenvalues leads to non-monotonicities in the evolution of the variables. In our case, this leads to some jumpiness during the first periods after a policy change. After an initial drop, the probability of imitation

\footnotetext{
${ }^{20}$ Still, some parameter choices yield indeterminacy.
} 
jumps above its initial level and gradually declines to a new higher steady state. Innovation drops and gradually rises until it hits its new higher steady state equalling imitation. Since the rate of imitation is generally above that of innovation in transition, this implies that Southern technology is catching up with that of the North, as reflected by an increase in $\hat{Q}$. With higher steady-state rates of technological progress, world growth increases. This demonstrates the dynamic benefits for the South of increased trade with a more developed region, even if it ends up specializing in imitative activities.

The first two columns of Table 2 show the steady-state values of key variables before and after Southern trade liberalization. Beyond the increase in growth and the relative level of Southern technology, we observe an increase in international competitiveness. This is seen in the increase in the share of sectors located in the North but facing Southern competition. At the same time, the share of sectors located in the South decreases. Together these demonstrate that both Northern and Southern firms are facing increased international competition. In the end, it is this increase in international competition that pushes up the rate of innovation and growth.

Table 3 presents the compensating variations for the North and the South. Following Lucas's (1987) methodology, these represent the percentage change in the equilibrium path of consumption under initial conditions necessary to make the household indifferent between the South maintaining tariffs of $5 \%$ and lowering them to $1 \%$. The South unambiguously benefits from this increased openness to Northern imports. Overall, the South would require a $2.2 \%$ increase in the equilibrium path of consumption under initial conditions to be willing to maintain its tariffs. However for the North, the costs of transition dominate the steady-state welfare gains. When these costs of transition are included, Northern welfare falls despite the higher future steady-state growth rate. The North would be willing to give up about $.3 \%$ of their initial equilibrium consumption path to avoid this increased competition from Southern imitators.

Notice that if one considers only the steady-state effects, both the North and the South gain from Southern trade liberalization. Table 3 shows that they would require a $.4 \%$ increase in their initial consumption path to be willing to have the South not liberalize its trade. However, there are transition costs, borne principally by the North. As we see in the lower right hand panel in 
Figure 1, the North is forced to pull resources away from consumption and towards research. The transition cost is sufficiently large that the welfare loss during transition outweighs the steady-state welfare gain for the North.

We now consider Southern trade liberalization concurrent with imposition of low levels of IPRs. Specifically, we force Southern imitators to pay a licensing fee to Northern firms. We model this as raising the fixed cost of imitative research, while lowering the fixed cost of innovative research. Figure 2 shows the evolution of the key variables during the transition to steady state. The paths are quite similar to those in Figure 1. The main difference is that the Northern interest rate is slightly higher in this experiment and the Southern interest rate both rises more quickly in the initial periods and then reaches the new higher steady state faster. Again, the Southern technology level increases relative to that in the North. The third column in Table 2 shows the steady state for this experiment. We see that the imposition of low-level IPRs leads to higher steady-state growth rates than Southern trade liberalization alone. Table 3 shows that, if we ignore the effects of transition, this experiment increases welfare for both countries relative to trade liberalization alone. Moreover, these long-run gains are now sufficiently large to dominate the transitional costs faced by the North. The North would now require a $.9 \%$ increase in the equilibrium path of consumption under initial conditions to be equally happy without Southern trade liberalization and increased IPR enforcement. Despite the higher IPRs, the South has an even greater welfare gain. Now the South would require a $3.2 \%$ (vs. $2.2 \%$ ) increase in its initial equilibrium consumption path to be willing to remain closed to intermediate goods imports and avoid any IPRs. As one would expect, the gain from increases in IPRs is greater (for both regions), the greater the openness of the South to imports of Northern intermediate goods.

These experiments demonstrate that the welfare loss to the North in the pure trade liberalization experiment is not due to trade per se, but rather to the lack of internationally enforced IPRs. There are positive spillovers from Northern innovation to Southern imitation, since each new innovation by Northern firms lowers the cost of Southern imitation. This is because, holding constant research experience, the cost of imitation depends negatively on the pool of goods left to be imitated, that is, it depends negatively on the technology gap between the two countries. The licensing fee, imposed 
in the IPR experiment, helps internalize this spillover.

\section{Conclusion}

This paper presents an endogenous model of growth through technological progress, demonstrating both static and dynamic benefits for less-developed countries when trading with developed countries. The concept of learning-to-learn in both imitative and innovative research is introduced, and a potential mechanism through which trade affects the diffusion of technology is modeled. International trade with imitation leads to feedback effects between Southern imitators and Northern innovators who compete for the world market. Both countries face transition paths dependent on the relative technologies in the two countries.

In our numerical examples, Southern trade liberalization leads to higher world growth, demonstrating dynamic benefits to the South of increased trade with a more-developed country. Northern welfare is lowered as a consequence of greater interaction with the South, despite increased world growth, because the transition to steady state entails large transition costs borne principally by the North. However, these losses are attributable to the lack of internationally enforced IPRs rather than trade liberalization per se. If the South increases IPRs at the same time that it opens to imports of intermediate goods, then both regions will increase their welfare. For the South, this welfare gain is greater than when opening to imports without imposing IPRs. Moreover, while particular welfare results depend on parameter choices, we demonstrate that focusing solely on steady-state results can lead to incorrect welfare interpretations.

This paper provides a dynamic argument, especially from the point of view of developing nations, in favor of free trade. This is particularly relevant for sectors with high technology components. Unfortunately, these are often the very sectors that developing countries choose to protect using trade barriers in an attempt to foster industrialization in infant domestic industries. Moreover, in a world where technology drives growth, and research in the South affects that in the North, it appears that the South may benefit by providing some degree of intellectual property rights to foreign firms. 


\section{References}

Aghion, P., Howitt, P., March 1992. A model of growth through creative destruction. Econometrica 60 (2), 323-351.

Barro, R. J., Sala-i Martin, X., 1995. Economic Growth. MIT Press, Massacusetts.

Barro, R. J., Sala-i Martin, X., March 1997. Technological diffusion, convergence, and growth. Journal of Economic Growth 2 (1), 1-26.

Ben-David, D., August 1993. Equalizing exchange: Trade liberalization and income convergence. The Quarterly Journal of Economics 108 (3), 653-679.

Ben-David, D., May 1996. Trade and convergence among countries. Journal of International Economics 40 (3-4), 279-298.

Ben-David, D., Rahman, A. A., 1996. Technological convergence and international trade. Working paper, University of Houston.

Bolton, M. K., Winter 1993. Imitation versus innovation. Organizational Dynamics 21 (3), 30-45.

Coe, D. T., Helpman, E., May 1997. International R\&D spillovers. European Economic Review 39 (5), 859-887.

Coe, D. T., Helpman, E., Hoffmaister, A. W., January 1997. North-south R\&D spillovers. The Economic Journal 107 (440), 134-149.

Coe, D. T., Hoffmaister, A. W., February 1999. Are there international R\&D spillovers among randomly matched trading partners? A response to Keller. Working Paper 99/18, International Monetary Fund.

Connolly, M., October 2003. The dual nature of trade: Measuring its impact on imitation and growth. Journal of Development Economics 72 (1), 31-55.

Dollar, D., March 1986. Technological innovation, capital mobility, and the product cycle in NorthSouth trade. The American Economic Review 76 (1), 177-190. 
Eaton, J., Kortum, S., Fall 1996a. Measuring technology diffusion and the international sources of growth. Eastern Economic Journal 22 (4), 401-410.

Eaton, J., Kortum, S., May 1996b. Trade in ideas: Patenting and productivity in the OECD. Journal of International Economics 40 (3-4), 251-278.

Eicher, T. S., Turnovsky, S. J., January 2001. Transitional dynamics in a two-sector non-scale growth model. Journal of Economic Dynamics and Control 25 (1-2), 85-113.

Glass, A., November 1997. Product cycles and market penetration. International Economic Review $38(4), 865-891$.

Grossman, G., Helpman, E., 1991a. Innovation and Growth in the Global Economy. MIT Press, Cambridge, MA.

Grossman, G., Helpman, E., May 1991b. Quality ladders and product cycles. The Quarterly Journal of Economics 106 (2), 557-586.

Keller, W., September 1998. Are international R\&D spillovers trade-related? European Economic Review 42 (8), 1469-1481.

Krugman, P., April 1979. A model of innovation, technology transfer, and the world distribution of income. Journal of Political Economy 87 (2), 253-266.

Lesley, R., 1924. History of the Portland Cement Industry in the United States. International Trade Press, Inc., Chicago, IL.

Mansfield, E., Romeo, A., December 1980. Technology transfer to overseas subsidiaries by U.S.based firms. The Quarterly Journal of Economics 95 (4), 737-750.

Mansfield, E., Swartz, M., Wagner, S., December 1981. Imitation costs and patents: An empirical study. The Economic Journal 91 (364), 907-918.

Obstfeld, M., Rogoff, K., 1996. Foundations of International Macroeconomics. MIT Press, Cambridge, MA and London, England. 
Rivera-Batiz, L. A., Romer, P., May 1991. Economic integration and endogenous growth. The Quarterly Journal of Economics 106 (2), 531-555.

Romer, P., October 1990. Endogenous technological change. Journal of Political Economy 98 (5), S71-S102, part 2: The Problem of Development: A Conference of the Institute for the Study of Free Enterprise Systems.

Rutherford, T. F., Tarr, D. G., March 2002. Trade liberalization, product variety and growth in a small open economy: A quantitative assessment. Journal of International Economics 56 (2), $247-270$.

Sokoloff, K. L., December 1988. Inventive activity in early industrial america: Evidence from patent records, 1790-1846. Journal of Economic History 48 (4), 813-850.

Stokey, N. L., August 1988. Learning by doing and the introduction of new goods. Journal of Political Economy 96 (4), 701-717.

Thomson, R., June 1987. Learning by selling and invention: The case of the sewing machine. Journal of Economic History 47 (2), 433-445, the Tasks of Economic History.

van Elkan, R., August 1996. Catching up and slowing down. Journal of International Economics $41(1-2), 95-111$.

Young, A., May 1991. Learning by doing and the dynamic effects of international trade. The Quarterly Journal of Economics 106 (2), 369-405. 
Table 1: Parameter Descriptions

\begin{tabular}{ll}
\hline$\rho=.02$ & subjective discount rate \\
$\theta=3$ & $\frac{1}{\theta}=$ constant intertemporal elasticity of substitution \\
$\alpha=0.7$ & labor share in production \\
$q=1.5$ & size of quality improvements \\
$\sigma=3.5$ & elasticity of cost of imit. w.r.t. $\hat{Q}$ \\
$\beta_{I}=0.9$ & spillover from innov. \\
$\beta_{C}=0.6$ & spillover from imit. \\
$\zeta_{I}=6$ & fixed cost of innov. \\
$\zeta_{C}=2$ & fixed cost of imit. \\
$A_{N}=3.5$ & N. productivity parameter \\
$A_{S}=3$ & S. productivity parameter \\
$L_{N}=5$ & N. work force \\
$L_{S}=6.25$ & S. work force \\
$\eta_{1}=2$ & elasticity of $\omega$ w.r.t. $\frac{M}{Q_{N}}$ \\
$\eta_{2}=1.5$ & elasticity of $\omega$ w.r.t. $F$ \\
$t=0.01$ & ad-valorem transport cost \\
$F=0.0037$ & transportation and communication infrastructure \\
$\tau_{X_{N}}=0.01$ & N. intermediate goods tariff \\
$\tau_{Y_{N}}=0.01$ & N. final goods tariff \\
$\tau_{X_{S}}=0.01$ & S. intermediate goods tariff \\
$\tau_{Y_{S}}=0.01$ & S. final goods tariff \\
\hline
\end{tabular}


Table 2: Steady-State Values

\begin{tabular}{cccc}
\hline & S. Tariffs $=.05$ & S. Tariffs $=.01$ & $\begin{array}{c}\text { S. Tariffs }=.01 \\
\text { Licensing Fee }=.15\end{array}$ \\
Innovation Rate $\left(p_{I}\right)$ & 0.2124 & 0.2148 & 0.2205 \\
Interest Rate & 0.1410 & 0.1423 & 0.1455 \\
Growth Rate & 0.0403 & 0.0408 & 0.0418 \\
$\hat{Q}$ & 0.1644 & 0.2682 & 0.2910 \\
$n_{S}$ & 0.4406 & 0.4398 & 0.4381 \\
$n_{N S}$ & 0.3130 & 0.3138 & 0.3158 \\
$n_{N N}$ & 0.2465 & 0.2464 & 0.2462 \\
\hline
\end{tabular}


Table 3: Compensating Variations of Aggregate Consumption (\%)

\begin{tabular}{ccc}
\hline & S. Trade Liberalization & $\begin{array}{c}\text { S. Trade Liberalization } \\
\text { with Licensing Fee }\end{array}$ \\
$\begin{array}{c}\text { Steady-State Only } \\
\text { North and South } \\
\text { Transition Plus St.-St. } \\
\quad \text { North }\end{array}$ & 0.4 & 1.4 \\
$\begin{array}{c}\text { Transition Plus St.-St. } \\
\text { South }\end{array}$ & -0.3 & 0.9 \\
\hline
\end{tabular}



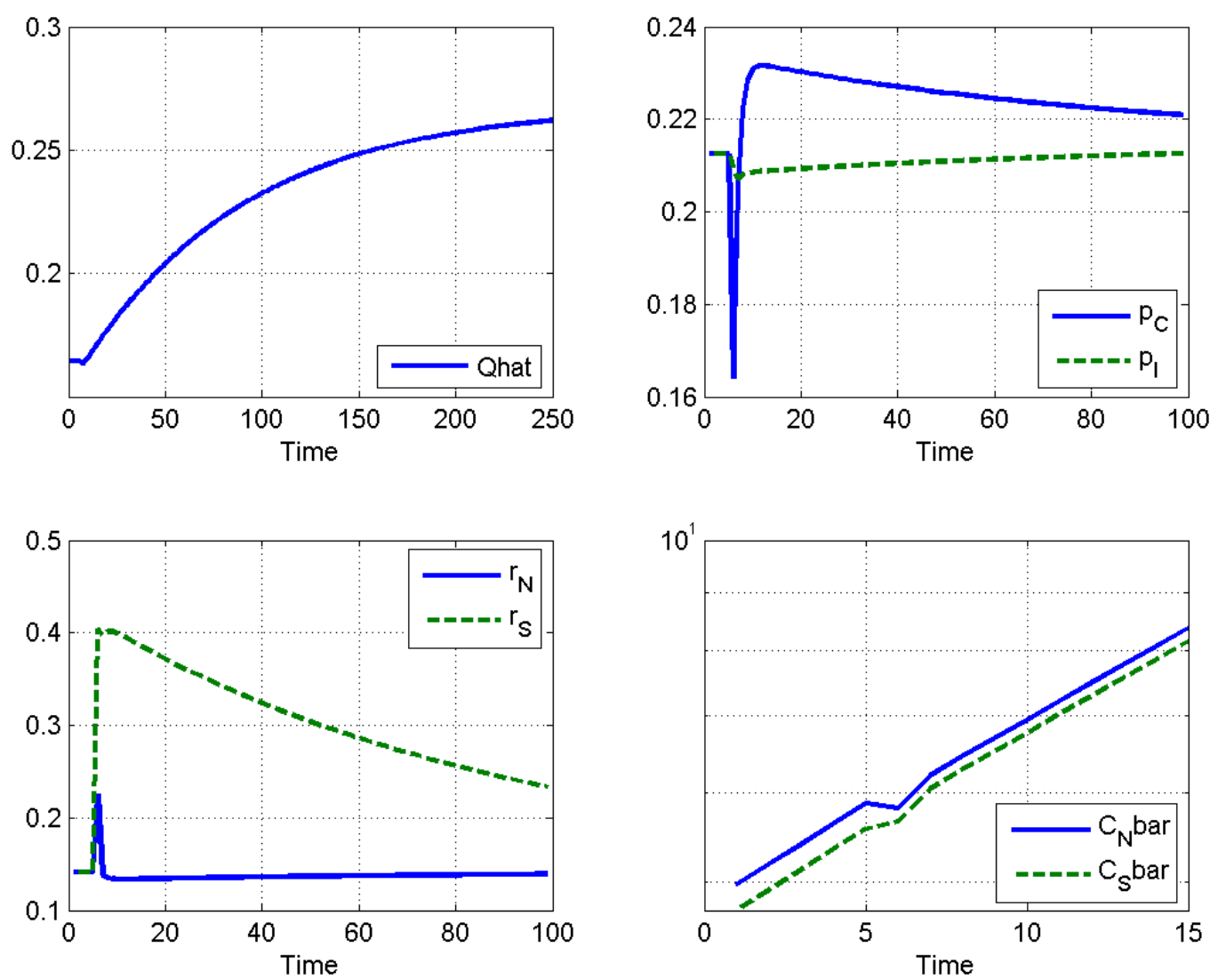

Figure 1: Experiment 1: Southern Trade Liberalization 

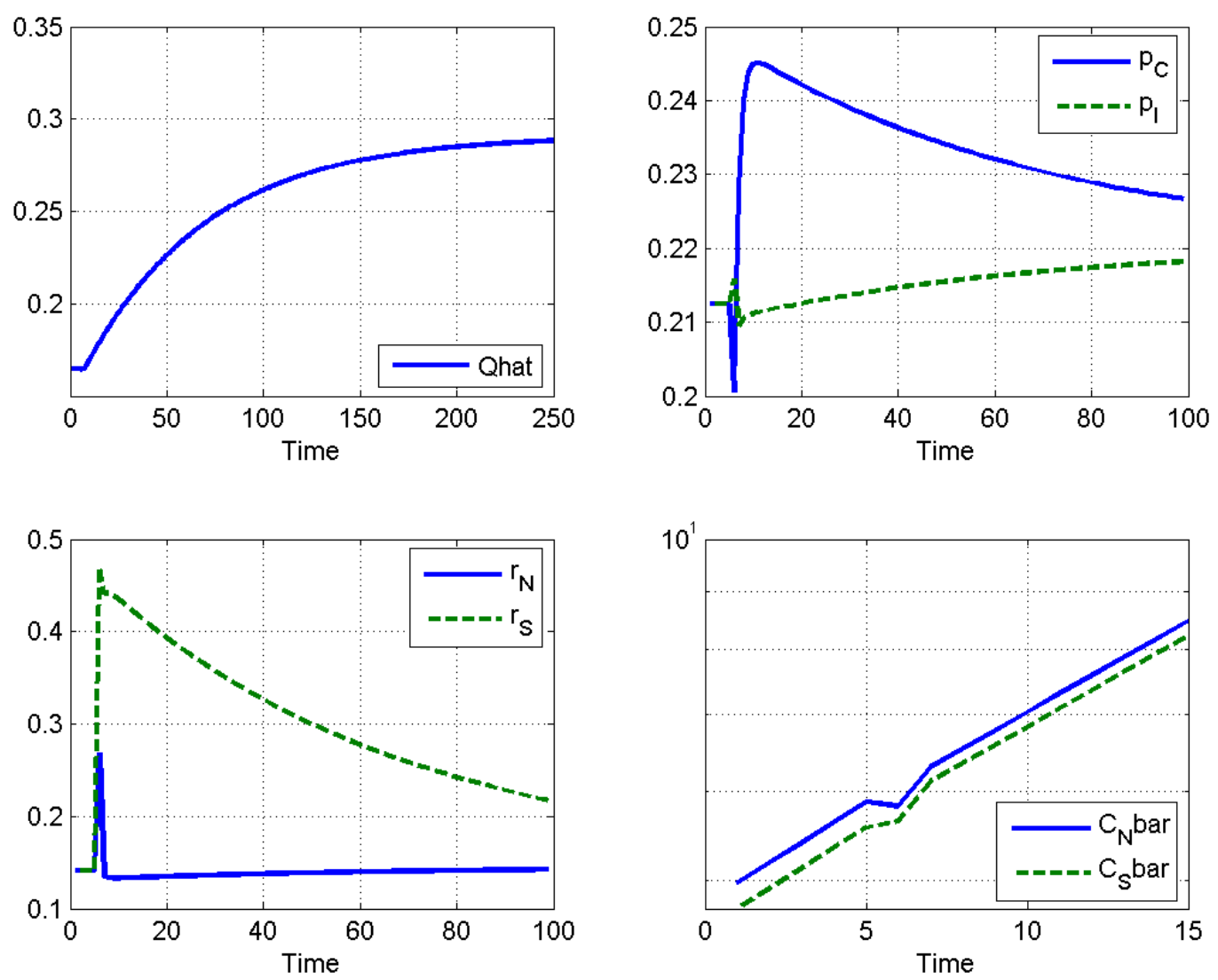

Figure 2: Experiment 2: Southern Trade Liberalization with IPRs 